\title{
Coloured Vowels: Wittgenstein on Synaesthesia and Secondary Meaning
}

\author{
Michel ter Hark
}

Received: 8 January 2009 / Revised: 2 February 2009 / Accepted: 16 March 2009 /

Published online: 29 April 2009

(C) Springer Science + Business Media B.V. 2009

\begin{abstract}
The aim of this article is to give both a sustained interpretation of Wittgenstein's obscure remarks on the experience of meaning of language, synthaesthesia and secondary use and to apply his insights to recent philosophical discussions about synthaesthesia. I argue that synthaesthesia and experience of meaning are conceptually related to aspect-seeing. The concept of aspect-seeing is not reducible to either seeing or imaging but involves a modified notion of experience. Likewise, synthaesthesia involves a modified notion of experience. In particular, the concept of synthaesthesia involves a secondary use of 'experience' and hence is intrinsically dependent on the primary use of language. Recent discussions tend to overlook this distinction between the primary and secondary use of language.
\end{abstract}

Keywords Wittgenstein $\cdot$ Synaesthesia $\cdot$ Aspect-seeing $\cdot$ Neuroscience . Ramachandran $\cdot$ Experience of meaning $\cdot$ Imaging $\cdot$ McGinn

\section{Introduction}

In the second part of his Philosophical Investigations, Wittgenstein discusses a number of evasive psychological phenomena that are interestingly related to current discussions in psychology and neuroscience about synaesthesia (which means literally 'joined sensation'). For instance, Wittgenstein describes the case of 'colourgrapheme synaesthesia' when he says: "For me the vowel $e$ is yellow" (PI, p. 216). On the same page, he gives his famous example of embodied weekdays: "Given the two ideas "fat" and "lean", would you be rather inclined to say Wednesday was fat and Tuesday lean, or the other way round? (I incline to choose the former).' (PI, p. 216). This example seems related to experiencing colours for days of the week, which is not uncommon among synaesthetes. Indeed, if synaesthesia is defined as a conscious experience of systematically-induced sensory attributes that are not experienced by most people under comparable conditions, then Wittgenstein is

\footnotetext{
M. ter Hark $(\bowtie)$

Faculty of Philosophy, University of Groningen, Groningen, The Netherlands

e-mail: michel.ter.hark@rug.nl
} 
concerned here with synaesthesia (Grossenbacher and Lovelace 2001). On other definitions of synaesthesia, however, Wittgenstein's interest seems to be broader, especially when his discussion of phenomena of 'meaning-experience' (or, to experience the meaning of a word) is taken into account. ${ }^{1}$ In this paper, I will use the term synaesthesia loosely and to cover phenomena of meaning-experience as well. The study of synaesthesia enjoys a controversial reputation. Some scientists have dismissed it as an illusion or a contrivance, whereas others have claimed that synaesthetes have a special aptness for the use of metaphors. Recently, however, neuroscientists and psychologists have accumulated evidence showing that synaesthesia is a genuine sensory and perceptual phenomenon, albeit related to mental imagery (cf. Baron-Cohen et al. 1996; Ramachandran and Hubbard 2001).

The aim of this paper is to understand the meaning and point of Wittgenstein's remarks about synaesthesia, meaning-experience and related phenomena. Many commentators have set them apart as 'curiously idiosyncratic' or have considered them as merely interesting for aesthetics (cf. Tilghman 1984; Budd 2006). In my view, however, they form an integral part of Wittgenstein's philosophy of psychology. A subgoal of this paper is to consider the consequences of a Wittgensteinian description of synaesthetic phenomena broadly conceived for the current debate about whether synaesthesia is a genuine sensory phenomenon or just a metaphor. I will argue that the concept of synaesthetic experience is related to aspect-seeing. Like aspect-seeing and meaning-experience, the concept of synaesthetic experience implies a secondary use of experiential concepts. As a consequence, the currently debated question whether synaesthesia is a sensory experience, a form of mental imagery, or perhaps even a fancy is misleading and overlooks the extent to which the concept of experience is 'modified' by the use of language.

\section{Synaesthesia in Wittgenstein's Writings}

Recent empirical psychological studies suggest that synaesthesia, and especially 'lexicalcolour synaesthesia' tends to be elicited by items belonging to conventional schemes, such as letters, digits, days of the week, months of the year (Rich et al. 2005). The synaesthetic colours (the 'concurrents' as they are also called in the literature) may be aroused by the visual appearance of a printed item, or by its sound when spoken aloud (the 'inducers'). ${ }^{2}$ The experiences are automatic, and extremely difficult to suppress, although they may be modulated by attention (Mattingley et al. 2006). The nature of the experience itself is akin to that of a conscious perceptual event (Ward and Mattingley 2006). Consistency over time of synaesthetic concurrents elicited by specific inducers has been noted repeatedly. ${ }^{3}$ Not until 1987, however, did BaronCohen et al. (1987) develop a diagnostic test for synaesthesia, now known as the Test of Genuineness. Synaesthetes typically appear to show a high consistency in their

\footnotetext{
${ }^{1}$ For instance, synaesthesia is often defined as the condition in which stimuli in one sensory modality elicit anomalous experiences in another modality. For example, the sound of a particular piano note may be 'seen' as a unique colour.

${ }^{2}$ P.G. Grossenbacher \& C.T. Lovelace (2001) introduced this distinction.

${ }^{3}$ E.g. Galton 1883; Ginsberg 1923.
} 
inducer-concurrent pairings. High consistency has increasingly become an essential precondition for classifying an individual as having synaesthesia. In a recent large-scale study, it was also found that there was a striking consistency in the colours induced by specific letters and digits across the sample as a whole, including synaesthetes and nonsynaesthetes. For instance, it was found that the vowel $a$ predominantly arouses the colours red and blue, and that $e$ and $i$ tend to be yellow and white (cf. Marks 1975, 308; Rich et al. 2005, 71). Synaesthesia is not associated with obvious brain pathology or with general cognitive dysfunction. Some claim that it may be linked to certain types of mental ability, such as a facility for using metaphor, musical aptitude, creativity. ${ }^{4}$ Some claim that it is probable that the brains of synaesthetes possess unique structural and functional properties (cf. Ward and Mattingley 2006). There is a wealth of studies investigating the physiological (neuro-cognitive) underpinnings of synaesthesia. ${ }^{5}$

Many of the preceding features are referred to by Wittgenstein in his remarks on synaesthetic experiences. Thus, one finds in his work several references to synaesthetic experiences prompted by inducers that are part of a conventional scheme, in particular weekdays, vowels and numbers. Some of his specific examples, e.g. 'e is yellow', are consistent with the general pattern found among synaesthetes and non-synaesthetes. It is not the purpose of this paper to speculate about whether Wittgenstein himself was a synaesthete, yet it is interesting to note that some of his remarks about synaesthesia have a striking biographical dimension. A clear example is his discussion of weekdays. In Philosophical Investigations, he concludes this discussion by saying that 'fat Wednesday' and 'lean Tuesday' might be associations from childhood, but that his philosophical investigation says nothing about such possible causes. In an unpublished manuscript, however, he does speculate about the origin of his particular associations. He observes that weekdays have a special character for him, almost a certain colour. Then he explains: Monday, Tuesday and Friday are fat, and the others, apart from Sunday, are meagre; Tuesday is yellowish and blackish. He traces his association of 'fat' and Wednesday and of 'lean' and Tuesday back to his childhood experience of having been taught by two female teachers that visited him on alternate days during the week. ${ }^{6}$ This example suggests that in Wittgenstein's own case particular inducerconcurrent pairs arose early and remained stable over time.

The related phenomenon of meaning-experience is initially described in terms of the invented syndrome of 'meaning-blindness', which is reminiscent of William James's notion of 'soul-blindness.' What a meaning-blind person would miss is the experience of being suddenly struck by the meaning or the physiognomy of an isolated word. A meaning-blind person would not be able to understand the command "Say "bank" and mean it as the financial institution,' or 'Say "March" and mean it as the verb, not the noun.' Proper names would be simply bearers of information for her, but not 'loaded with meaning.' Neither would she understand it when others speak of coloured vowels or embodied weekdays. Meaning-experience refers to the physiognomic perception of

\footnotetext{
${ }^{4}$ Ramachandran and Hubbard (2001). There are, however, no empirical data to support this view.

${ }^{5}$ See for an overview the recent special of Mattingley et al. (2006).

${ }^{6}$ Wittgenstein unpublished manuscript 131, p. 173-174. See also PI, p. 216. The references to the unpublished writings follow von Wright's catalogue (von Wright 1982).
} 
words, which in its turn is related to synaesthesia. ${ }^{7}$ Owing to their use in countless situations words come to have a 'familiar physiognomy'. The use has impressed itself upon one, much in the way in which human faces impress themselves. Words come to absorb their meaning or use and so become an actual likeness of their meaning (cf. Wittgenstein PI, p. 218). The semantic role of a proper name, for instance, is that of a singular referring expression, replaceable, in principle, by numbers. As Wittgenstein notes, however, one could not say of prisoners' numbers what Goethe said of person's names: '...a man's name is not like a mantle, which merely hangs about him, and which, perchance may be safely twitched and pulled, but is a perfectly fitting garment which has grown over and over him like his very skin, at which one cannot scratch and scrape without wounding the man himself'(Goethe 1971, 14; Wittgenstein RPP1, 326). For Wittgenstein himself the name 'Goethe' had a particular physiognomy. This was especially evident to him when reading his signature. The written name intimated something Goethian to him, and to that extent it was like a face to him, for the same might be said of the poet's face. ${ }^{8}$ In such a case one experiences the name as filled with its meaning and wearing its meaning like a face.

The phenomenon of meaning experience is not restricted to proper names which, after all, do have an enormous significance in most cultures. Substantives, verbs and conjunctions have a physiognomy too. One may even experience the meaning individual letters have. In his discussion of the phenomenon of 'mental blindness', William James writes that printed letters signify sounds and certain articulatory movements. In normal cases, he notes, the sight of words awakens the idea of their sound. ${ }^{9}$ In his discussion of the concept of reading in Philosophical Investigations 156-171, Wittgenstein speaks about the unity of a letter and its sound: '...when one reads, letter and sound form a unity - as it were an alloy... When I feel this unity, I might say, I see or hear the sound in the written word.' (PI, 171). The original manuscript version of this remark includes the following example: the appearance of the letter $e$ forms a unity with its sound, so that one might say 'That is an e'. ${ }^{10}$ Or to take another example from the same manuscript: while reading the word 'yes' it is impossible to distinguish the written and the spoken word, and one could say that pronouncing it is a part of the perception of the sign itself. ${ }^{11}$ Here we not only have a case of meaning experience but also one in which the item described (i.e. the written letter) seems of the wrong category for the subject of description (i.e. seeing the sound in the written letter). Also discussed by him is the tendency, sometimes reported

\footnotetext{
${ }^{7}$ According to Werner (1966), synaesthesia is directly connected to physiognomic perception, which is defined as the perception whereby the perceiver tends to suffuse percepts with an emotion, affective, or expressive quality. As Marks (1996, p. 44) observes, physiognomy commonly applies to expressive properties of the human body, especially the face, but the term 'physiognomic perception' has come to take a broader meaning, referring more generally to dynamic, evocative or expressive properties, for example, the appearance of a thundercloud as threatening.

${ }^{8}$ Cf. Wittgenstein RPP1, 336, 338. In a manuscript he says that the name even has a specific colour: brown-yellow, and adds 'perhaps because of the vowels ö and e'. (Wittgenstein, unpublished manuscript 131, p. 149) Wittgenstein had a similar experience with Schubert's name (Wittgenstein LW, 69).

${ }^{9}$ William James (1890) vol. 1, 48-49. With mental blindness the sight of words fails to awaken the idea of their sound.

${ }^{10}$ Wittgenstein unpublished manuscript 115 , pp. 211-12

${ }^{11}$ Wittgenstein unpublished manuscript 115, pp. 211-12
} 
by synaesthetes as well, to 'gender' vowels. The vowel $a$ sounds and feels different in a masculine noun (Agricola) than in a feminine noun (puella). ${ }^{12}$ In the former it sounds 'aggressive', 'masculine', in the latter soft and feminine. Finally, Wittgenstein discusses what some call weak synaesthesia and others sense-related metaphors: 'warm colour', 'deep sound', 'deep sadness', etc. (cf. Wittgenstein BB, 137).

\section{The Urge to Hypostatise}

The question that now has to be answered is why Wittgenstein was interested in synaesthesia? The received view has it that by means of synaesthetic phenomena Wittgenstein seeks to supplement his earlier view of the meaning of a word as its use in the language (e.g. Kripke 1984, Johnston 1993, Mulhall 2001). On this account, the view of language as a system of rules developed in Part one of the Investigations leaves no room for the 'innerness' of meaning, for the 'control I have over what I say' (Cavell 1979, 36). In his last writings, Wittgenstein develops a two-tiered account of meaning: meaning as use plus meaning as experience. According to Mulhall (2001), for instance, the remarks about meaning experience have the purpose of reminding us of the pervasiveness of our attitude towards individual words. For instance, no one would be inclined to say that words can lose their meaning and become mere sounds when repeated too often if they standardly perceived them as mere sounds in the first place. He speaks of 'continuous meaning perception' as an essential feature of linguistic understanding. On the view that I defend, however, the reflections on synaesthesia are meant to show how easily we fall into the trap of hypostatizing special experiences or images. To see this more clearly consider first a passage from James which may well have cued Wittgenstein's critical thoughts on the 'if-feeling' in section vi of Part Two of the Investigations:

'When we read...is it true that there is nothing more in our minds than the words themselves as they pass? What then is the meaning of the words which we think we understand as we read? What makes that meaning different in one phrase from what it is in the other? 'Who?' 'When?' 'Where?' Is the difference of felt meaning in these interrogatives nothing more than their differences of sound? And is it not (just like the difference of sound itself) known and understood in an affection of consciousness correlative to it, though so impalpable to direct examination?' (James 1890 vol. 1, 252).

'We ought to say a feeling of and, a feeling of if, a feeling of but, and a feeling of $b y$, quite as readily as we say a feeling of blue or a feeling of cold' (James 1890, 245-6).

Wittgenstein would have no objection with James's concern with experiences of meaning; he would (only) object to the phrase 'quite as readily' in the preceding quote. This presumes not just that experiences of meaning can be compared with the various paradigmatic cases of experience, but rather that they must be so compared. For if using words would not make a difference to our experience, our understanding

${ }^{12}$ Wittgenstein unpublished Manuscript 116, p. 326. 
of language would not be different from the 'understanding' attributed to a mechanism operating with signs of various sorts. But this is already to be taken in by the grammar suggested by 'something besides'.

The urge to hypostatize elusive experiences is a deep-seated intuition about the genesis of which Wittgenstein has much to say. In a series of scattered remarks he delves into what I call the psychological predicament of the philosopher (or scientist) determined to explain the nature of conscious experience. A particular motive for hypostatizing experiences arises when thinking about the exceptional, the unfamiliar. Thus, James in fact concludes on the basis of his experience of a foreign language, i.e. the experience that the words have no meaning, to the presence of experiences of meaning underlying the use of one's native language. Consider now the following remark which I think is meant as an analogy:

'While I write, do I feel anything in my hand or in my wrist? Not generally.

But still, wouldn't it feel different, if my hand were anaesthetized? Yes. And is that now a proof that I nevertheless do feel something when I move my hand in the normal way? No, I believe not.' (RPPI §208)

By analogy, in normal linguistic intercourse we do not have if-feelings when making a conditional statement in the course of a discussion. Only in special situations the if-feeling may arise, e.g. when doing introspective philosophy or psychology. It was James's talent to make his readers aware of a variety of experiences of meaning, but what is perhaps his most effective example is a linguistic version of anaesthesia, i.e. the feeling that the meaning of a word may slip away when repeated several times. Thus, Wittgenstein asks in another remark whether a word, as it is used in normal circumstances, does not perhaps feel as it does when it has lost its meaning through being often repeated: 'You certainly can't testify from your memory that the contrary is true. But one merely finds that a priori it can't be otherwise' (RPPI §194). The inference is no more than an a priori hypostasis of experiences caused by failing to see the special (mental) condition in which meaning-experiences are reported. This condition is like the one in which a person notices a certain aspect of a word familiar to him and which never occurred to him before. From this it seems to follow that he must have also been aware of a different aspect, i.e. an aspect under which he always, in normal conditions, understands these words. ${ }^{13}$ For instance, because a certain word joke, e.g. Wittgenstein's favourite example 'Weiche, Wotan, weiche', prompts a comic experience, it is concluded that when Weiche ('retreat') and weiche ('soft') are used in normal circumstances they must also be experienced in a specific way. ${ }^{14}$ What one fails to see here, however, is that had one not 'discovered' the experiences in the special condition, one would never have thought that the words as used in normal conditions are experienced in a certain way. That is, when reading or saying 'if' in normal conditions one has no experiences whatsoever, despite the fact that in other circumstances one may 'experience' the word when looking at it closely and

\footnotetext{
${ }^{13}$ See RPPI $\$ 539$ for a clear application of this argument to aspect-seeing.

${ }^{14}$ Wittgenstein refers to this joke in RPPI $§ 77$. The words can be read as an instruction for Wotan to retreat and, on the other hand, as an answer to Wotan's question about whether one has a preference for hard-or soft-boiled eggs. See also Schulte 1993, p. 68.
} 
pronouncing it with a certain emphasis. ${ }^{15}$ The question now is, what does it mean to speak of 'experience' in the exceptional, sometimes even deviant cases?

\section{Imaging and Seeing-as and Synaesthesia}

In the recent scientific literature, synaesthetic phenomena are usually classified as a kind of percept. Because synaesthetic experiences can also arise from the mere thought of a particular inducer, it is concluded that mental imagery might also have an important role in the generation of synaesthesia (Rich and Mattingley 2002, 44). Some even speak of synaesthestic experience in general as a 'percept or image'. This implies a Humean conception of the mind according to which mental images are in the same class as visual and auditory impressions. Hence synaesthetic experiences are conceived of as a type of percept - an anomalous or degraded percept, but a percept nonetheless. The only difference, according to the Humean conception, is a gradual one: the 'force and liveliness' with which images present themselves lack the intensity of impressions. Even so, images are impressions, if pale-faced and featureless ones (cf. Martino and Marks 2001, 62). As can be learned from Wittgenstein's reflections on psychological concepts, however, this inventory of the mind misses crucial logical differences between percepts on the one hand and mental images on the other. ${ }^{16}$ Therefore, in order to be able to answer the conceptual question of how synaesthetic experiences have to be classified, it is necessary to point out the distinguishing marks of mental images.

A logical criterion for an experience to be included in the class of senseexperiences is that it should supply information, rightly or wrongly, about the external world (cf. Wittgenstein RPP2, §63). By contrast, a mental image tells us nothing about the world. Wittgenstein explains this criterion in terms of the idea that mental images are voluntary ('subject to the will'), whereas sense-experiences are involuntary. It is in virtue of their being voluntary that mental images supply no information about the world (cf. RPP2, §80).

Wittgenstein's basic thought about the concept of imaging is that it is something one does, whereas seeing is the concept of something that happens. On the Humean account, instead, mental images are merely a passive, and less vivid, replica of an earlier percept. As a faint percept images are no less involuntary than (vivid) percepts. The idea that images are voluntary should not be understood as implying that images are always produced by and responsive to the will. It is a familiar experience for mental images to pop into the mind, to resist the effort to eliminate them. Recently Colin McGinn, also drawing on Wittgenstein, distinguished three points at which mental images may be subject to the will: their inception, their course and their termination (cf. McGinn 2004, 14). In some cases images may not be voluntary at their inception, but are typically subject to the will in their course and

\footnotetext{
${ }^{15}$ But in this latter case the question has to be answered how the use of 'experience' relates to the use of this word in paradigmatic cases. See further below, Sections 3, 4 and 6.

${ }^{16}$ For an early exposition of Wittgenstein's views see M. Budd (1989) and M.R.M. ter Hark (1990). Recently C. McGinn (2004) has applied Wittgenstein's ideas to the topic of the imagination. McGinn does not deal with synaesthesia or meaning experience, though.
} 
termination. Even when images are resistant to the will in all three phases, McGinn argues, it is still in principle subject to it - though this may require greater effort. McGinn seems to miss here the logical point involved. The point is not that images are in principle subject to the will because a person can always decide to follow a therapy to fight them, but rather that even in such extreme cases a person does not adopt the observational attitude towards his images. To say that imaging is voluntary is to make the same sort of claim as saying that imaging has nothing to do with observing. On the other hand, the concept of seeing is related to the concept of observing precisely because perception supplies information about the external world. In the sense in which seeing is related to looking, the observation has the feature of being able to surprise us. If one observes a scene one may be ignorant about what is going to happen, or eager to gather more information about the external optical picture. That impressions are in this sense involuntary is not just a matter of the psychological architecture but constitutive of what we mean by 'impression'. We would no longer have the concept of colour, for instance, when we could see colours the way we wanted. Even the concept of impression would lose its sense and with it the concept of an external world, of truth, etc. Perceiving gives information about reality in the sense that, given the percept's independence of the will, impressions can serve as a touchstone or means of verification of what takes place in reality (cf. ter Hark 1990). One cannot be surprised in the same sense by having mental images. An image, as Sartre also put it, 'teaches nothing, never produces an impression of novelty, and never reveals any new aspect of the object. It delivers it in a lump. ${ }^{17}$ The image does not supply information about reality in the sense that, given the dependence of the image on the will, images cannot serve as a touchstone or means of verification of what takes place in reality. Thus, even when images come unbidden, and resist being eliminated, they are not what one is looking at.

This view implies that it makes no sense to ask whether images and senseimpressions can be confounded. As Wittgenstein says: 'The dagger which Macbeth sees before him is not an imagined dagger. One can't take an image for reality nor things seen for things imagined. But this is not because they are so dissimilar'(cf. Wittgenstein RPP2 §85). To be sure, when they are strikingly similar they cannot be confused either. Fancies, hallucinations and also after-images are involuntary. A person may adopt the attitude of observation towards them, they can surprise him and he can wait to see how they will change. So it makes sense for the person to ask whether what he is experiencing is a hallucination or a sense-impression. But when a person visualizes something he is aware that his attitude is not one of observation in which he looks at something to discover what properties of the object might be revealed. Lacking the attitude of observation the person cannot mistakenly believe that he is observing either. Macbeth therefore is not troubled by a lively imagination but by a fancy or hallucination.

Consider now the application of the preceding discussion to the question whether synaesthesia is a percept. Included in the definition of synaesthesia is that it is an involuntary experience. In the literature this is clearly an empirical or statistical

\footnotetext{
$\overline{17}$ The similarity between Sartre's account of the imagination and Wittgenstein's is pointed out in M.R.M. ter Hark 1990. Jean Paul Sartre 1940, p.23.
} 
criterion. So McGinn's preceding questions are applicable here: is the experience involuntary at its inception, its course or its termination? Moreover, if one takes account of the distinction between strong synaesthesia and weak synaesthesia differences emerge at the empirical level. Weak synaesthesia is voluntary in its inception - a question is raised, e.g. 'What colour does the word 'Wednesday' have?'- and probably in its course and termination. Strong synaesthesia is stimulusdependent synaesthesia and, as this term suggests, involuntary in the sense that one finds oneself compulsively experiencing specific colours when specific vowels are read or heard or even imagined. Yet here too there are people who have complete control over their synaesthesia as well as people who are able to induce synaesthetic experiences but not to prevent them (cf. Rich et al. 2005, 67). Stimulus-dependent synaesthesia, however, would logically count as a sense-experience if and only if it would inform us about the external world, and hence, if we could adopt the observational attitude. Here we should take account of the distinction between the 'inducer' and the 'concurrent'. The 'inducer', or the optical picture (e.g. the black printed letters), is triggered by the senses and hence observed, but the 'concurrent' (e.g. the synaesthetic colour) is not. The person reads or pronounces the letters and words, but he is not gazing at the synaesthetic colours hoping to learn what kind of information they provide about reality. Indeed, if the person would nevertheless expect to learn more about his experience in this sense by inspecting and observing the concurrent, the absurd consequence would be that he might take the vowel into better light in order to see what colour it really has. Because synaesthesia does not share the logical marks that sense-experiences (including hallucinations and afterimages) have, it follows that it is senseless to suppose that a subject might confuse synaesthetic colours and real colours. In the literature it is often reported that synaesthetes actually do not confuse induced colours and real colours, but the truth is that it makes no sense to suppose this. A person who is having a synaesthetic experience is aware that his attitude is not one of observing (the concurrent) and so it is inconceivable that he mistakenly believes to be seeing real colours.

Is synaesthesia mental imagery? Synaesthesia, so my claim is, is a hybrid concept just as the concept of seeing-as or aspect-seeing. Aspect-seeing is conceptually related to mental imagery in being voluntary and not being informative, yet there is an optical representation which is triggered by the senses. In aspect-seeing a subject observes a drawing and suddenly notices that it can be seen either as a drawing of a duck or of a rabbit. Or the subject looks at a human face, and suddenly notices its likeness to another face. When a certain aspect is registered, however, the optical picture does not undergo any change in colour, form, or distance to the observer. That is why the change to two ways of seeing something is so mysterious, for how can a change of visual experience be accounted for if optically and geometrically speaking everything stays the same? This change of aspect is not to be compared with a shift in perspective. Plain seeing is almost continuously subject to shifts in perspective, and involves the continuous updating of one's beliefs about the perceptual stimuli. Because features of the optical picture actually change, one has epistemic grounds (i.e. information) for updating one's beliefs about what one perceives. What is surprising and paradoxical about aspect seeing, however, is that we feel that the face or the duck/rabbit figure is altogether different after the change of aspect, as if it had altered before our very eyes; and yet we know that there has 
been no such change (Wittgenstein LW 174). Because nothing has changed in the optical picture of one's perception one has no epistemic grounds for changing the visual report. Yet one is not deluded, for one knows that in the optical picture nothing has changed. Still, one is incomprehensibly compelled to report completely different things, one after the other. Furthermore, like mental imagery, aspect-seeing is voluntary. If a surface appears blue to one, one cannot see it red, and it does not make sense to say 'See the surface red.' We would no longer speak of things having colours when we could order someone to see colours as we wanted. But it does make sense to say 'See the surface as red' (cf. Wittgenstein RPP2 §474). Accordingly, aspect-seeing is not informative.

Synaesthesia and meaning experience, then, are like mental images in being voluntary or in supplying no information about external reality. On the other hand, they are like sense-experience because a person typically has the experience of coloured vowels by looking at vowels, or pronouncing them in a particular way. Moreover, like concrete sensory experiences and impressions, synaesthesia and meaning experience both have 'genuine duration' (cf. Wittgenstein Z 45-47). They are conceptually 'states' which have a beginning, an end, which can be clocked and interrupted by a shift in attention or a break in consciousness. In being linked to both sense experience and mental image, synaesthesia, just as the concept of aspectseeing, is a hybrid concept.

A hybrid concept, however, is not simply a concept of a 'mixed experience', as synaesthesia is often called. Synaesthesia and meaning-experience are concepts that involve a modification of the concepts of sensation and experience. The concept of experience here differs from the concept used when we speak of e.g. a sensation of intense pain. Yet this modified concept of experience also presupposes the more basic concepts of experience. Put otherwise, the concept of synaesthesia simultaneously presupposes and transforms the use of other concepts. In the case of synaesthesia, as I shall argue below, this conceptual dependency takes the specific form of a relation between what Wittgenstein calls the 'secondary use' and the 'primary use' of words.

\section{Metaphor and Secondary Use}

Consider this passage:

'Given the two ideas 'fat' and 'lean', would you be rather inclined to say that Wednesday was fat and Tuesday lean, or vice versa? (I incline decisively towards the former.) Now have 'fat' and 'lean' some different meaning here from their usual one? - They have a different use.- So ought I really to have used different words? Certainly not that.-I want to use these words (with their familiar meanings) here' (PI, p. 216).

The more general conception about the nature of language that Wittgenstein brings into focus here is that the transference of a word from one area to another need not be interpreted as implying a change (i.e. an extension) of the meaning of this word. It is not a matter of giving a word like 'fat' or 'yellow' a metaphorical sense, for as Wittgenstein observes about the expression 'For me the vowel $e$ is 
yellow', 'I could not express what I want to say in any other way than by means of the word "yellow"' (PI, p. 216). Neither is it a matter of word-ambiguity. Indeed, the characteristic feature of the linguistic shift involved in synaesthesia is that a word, e.g. 'fat' does not serve as a name for two different, yet related items. There is a difference in use, but it cannot be explained along standard lines, i.e. metaphorical transference or ambiguity. The distinctive feature of the transferred use of language here is precisely that the transferred word does not refer to something other than what it refers to in its home base. As Wittgenstein puts it, if he were asked what he really meant by 'fat' and 'lean' weekdays, he could not point at the features of the weekdays. He concludes that: "Here one might speak of a "primary" and "secondary" sense of a word. It is only if the word has the primary sense for you that you use it in the secondary sense.' (PI, p. 216).

Yet synaesthesia seems to invite precisely this metaphorical conception. Indeed, according to Marks, synaesthesia may be deemed 'a kind of perceptual metaphor, in which qualities of one class or modality of sensory-perceptual experience are transferred to another, as when colors are ascribed to tastes, pains or musical notes' (1996, 41). Marks's view goes back to the Gestaltpsychologist Wolfgang Köhler who in his influential book Gestaltpsychology (1929) argued that synaesthetic perception as well as physiognomic perception reveal the presence of deep similarities across different sense modalities. Thus he says: 'Brightness and darkness, for instance, are attributes of both auditory and visual experience. Again, if an object which we touch appears cool, its coolness somehow resembles visual brightness...' (1929, 223). Likewise, not only a surface which we touch but also the sound of a voice and the taste of a wine may be called 'smooth'. As examples of words used both for the description of subjective experiences and perceptual phenomena, Köhler mentions 'bitter feeling', 'soft mood', 'sweet love' and 'dark grief'. Köhler's objection to the claim that these are mere verbal analogies from which nothing can be inferred is interesting for our purposes. He says: 'I cannot accept this as an argument, however; for what we mean by an analogy is precisely a certain kind of resemblance.'(1929, 226) According to Köhler, 'there must be a principle which regulates the various applications.' (1929). And: 'This principle must also be operative when, in a lively description of inner facts, somebody invents a new transfer of terms, and again when others realize what they mean' (1929). The only principle he can imagine is that certain inner experiences and perceptual experiences resemble each other in certain respects.

Köhler's reasoning is also at the roots of recent neuroscience. Thus, Ramachandran and Hubbard claim that both synaesthesia and metaphor involve cross-activation of respectively perceptual maps and conceptual maps (cf. 2001, 17-18). They hypothesize that the angular gyrus performs a very elementary type of abstraction-extracting the common denominator from a set of strikingly dissimilar entities. Thus, when Shakespeare writes 'Juliet is the sun', our brains instantly understand this. You don't say, 'Juliet is the sun. Does that mean she is a glowing ball of fire?'...Instead, your brain instantly forms the right links, 'She is warm like the sun, nurturing like the sun, radiant like the sun'...(Ramachandran and Hubbard 2001, 16).

Metaphors work only if there is some important and readily noticeable similarity between two situations. A metaphor is a sort of figurative use of language in which the extension of the word is derived from the established sense on the basis of 
noticing a similarity. ${ }^{18}$ Significantly, however, neither Köhler nor his contemporary followers, even attempt to specify the respects in which particular synaesthetic and quasi-metaphorical uses of words are similar to the established use of words from which they are said to be derived. Insisting, as they do, that there must be a deep similarity underlying this use of words, therefore, may be no more than an a priori linguistic assumption. In particular, it may be no more than a deeply rooted assumption that when we use the same word of different things we must have been struck by a similarity.

Wittgenstein challenges this deeply rooted assumption common to Köhler and recent neuroscience. Thus, he asks whether it is a precondition for applying the same word to very different items that the person notice or experience a similarity between these items. For instance, we speak of both 'bodily strain' and 'mental strain', but what do these cases have in common, or in which respects are they similar (cf. Wittgenstein BB, 129). Should we say that mental strain and bodily strain are 'strains' in a different or slightly different sense of the word? If so, 'mental strain' is a metaphorical generalization of 'bodily strain' in virtue of a noticeable resemblance. We are certainly inclined to say that mental strain and physical strain are similar, but asked to indicate in which respect their similarity consists, what can we say? Can one say, what is common to them is a certain tension? This does not get us any further, for now the question is why we speak in both cases of 'tension'. Put otherwise, are we not just translating words into other words? (cf. Wittgenstein BB, 132). This does not mean that to speak of a similarity here is forbidden. If the point is to emphasize a difference with word ambiguity where two items are referred to by the same word, e.g. 'bank', but not in virtue of any similarity, it might be even relevant. The point rather is that if the similarity cannot be specified, it cannot be cited as a justification of one's use of words.

The search for a justification of transferred language is even more futile - and for that reason even more pressing - in the case of colour-vowel synaesthesia. In a series of passages, Wittgenstein imagines someone who has been taught the use of the words 'lighter' and 'darker' in the normal way and is asked to arrange a number of books in order of their darkness. Then he is asked to do the same with the five vowels in the order $u, o, a, e, i$. (cf. BB, 138-139). If asked why he put down this latter series he may reply that $o$ is lighter than $u$, and $e$ lighter than $o$. Perhaps we will object that vowels are not lighter or darker than other vowels in the way in which the colours of books may vary in darkness. Suppose he replies: 'I don't know, but e is lighter than o, isn't it?' (cf. BB, 139). A natural explanation, and one congenial to Köhler and recent neuroscience, would be to say that for the person 'lighter' and 'darker' mean something different from what this pair means to us, and that they 'somehow resemble' the established sense of words. The use of the word as applied to vowels would then be not just an analogy 'from which nothing can be inferred', but it would be justified in virtue of a resemblance with what the words in their established sense mean.

\footnotetext{
${ }^{18}$ It has been questioned whether this is very illuminating. Thus, it is said that it is explanatory only if the comparison implicit in a metaphor can be turned into an explicit, literal comparison or simile. Because many paraphrases themselves involve non-literal language, the absolute distinction between metaphor and simile is not tenable. But whether or not metaphors can be reduced to similes involving literal language, the making and understanding of comparisons is of fundamental importance in both.
} 
The metaphorical account of synaesthesia fails for several reasons. In the first place, it imposes a double cognitive operation upon synaesthetic experiences which is contradicted by self-reports. As these self-reports make abundantly clear, there is no question of a process of comparing, of first thinking of or even looking at colours before applying them to vowels. On the contrary, people make such judgements straight off. Secondly, subjects typically cannot say in which respects colours and vowels are similar. Indeed, they are completely at a loss to provide any sort of paraphrase. Accordingly, the synaesthete's use of the expression ' $e$ is yellow' has not amplified certain aspects of the established meaning of 'yellow' and suppressed other aspects. A fortiori, the synaesthete's use of words is not based on recognizing similarities. Thirdly, a metaphor is used to say something different from, though related to the established sense. By contrast, in ' $e$ is yellow' 'yellow' is not used to say something different from what it means in its established sense: one 'chooses' this word in virtue of its established or primary sense. An extension of the primary sense of the concept is precisely what is not found (and not wanted) in the expression of synaesthesia.

Still, there is a sense in which metaphor and secondary use seem related. A metaphor is somehow parasitic on the established sense of the relevant term. This established sense is always involved in the metaphor, for unless one understands the relevant established sense, one will not be able to understand the metaphor. An expression used in a secondary sense is also somehow parasitic on the primary sense. Moreover, both a metaphor and words used in a secondary sense depend on a preceding knowledge of the primary sense of the words. According to Wittgenstein, however, metaphors can always be paraphrased or at least explained, i.e. one does not have to use the metaphorical expression. By contrast, with synaesthetic experiences one cannot express what one wants to say by means of another word (with a different primary meaning). It is important to note that the 'cannot' here is meant logically. Wittgenstein here points to a categorical distinction between words used in a secondary sense and their use in their home base. As one might also say, he points to a difference in 'language-games'. Indeed, the basic point here is that the synaesthetic expression of experience is a new language-game added to, or built upon, the original home base of the words. By thus rephrasing the discussion about synaesthesia in terms of the interrelationship between different language-games, Wittgenstein makes clear that for him the discussion is logical rather than empirical or epistemological.

Other expressions he uses to indicate that a new language-game is involved are that we are inclined to use words (e.g. 'yellow' as applied to a black printed $e$ ) this way (PI, p. 216; LW, 789), that we are using them 'spontaneously' (RPP1, 125), or in a 'new' way (RPP1, 126). The mention of 'inclination' is meant to convey the fact that we have not learnt to use words in this way. We have not learnt by means of ostensive definition that the words might mean two different items, nor have we learnt to generalize the meaning of the words in virtue of noticing similarities. As a consequence, the relation of the use of these words to their use in their home base is completely different from the way the metaphorical use of words is related to the literal use of words. When we are using words in a secondary sense we are not operating with these words according to existing procedures. How then do people get to use these words? 
This of course is a basic question of Wittgenstein's philosophy of psychology which here takes a rather perplexing form. Many psychological concepts are used against the background of a pattern of primitive reactions and unquestioning responses. ${ }^{19}$ For instance, primitive pain-behaviour is a 'sensation-behaviour' which gets replaced by a linguistic expression of pain. Primitive reactions then are important for concept formation. If this is so, what are the primitive reactions in the case of words used in a secondary sense? The answer is: the words themselves. Put otherwise, in the case of a synaesthetic use of words the primitive reaction is a verbal reaction. That is, the inclination to use words in such and such a way, to use them 'spontaneously' so, is a primitive verbal reaction which as such marks the start of a new use of language. This new use of words necessarily presupposes the command and understanding of other words because the spontaneous formation of primitive reactions here is itself a use of words; words that necessarily come from other areas of language. ${ }^{20}$ The primary use of words, therefore, provides the necessary stage-setting for the secondary use. The secondary use simultaneously presupposes and transforms this primary use.

The primitive reaction of the synaesthetic use of words is verbal, yet qua primitive it is 'related' to the relevant experience in the same way as e.g. the primitive painbehaviour is 'related' to the sensation of pain. In both cases the primitive reaction is constitutive of the experience. In particular, this means that it would be a mistake to conceive of the inclination to use words in such and such a way, e.g. to say 'For me $e$ is yellow', as an (indirect) description of an (inchoate) experience. Rather, the psychological phenomenon is what we are inclined to say by means of such and such words. It is this use or role of the words which explains why we have to use the words we in fact use, why we cannot say what we want to say by means of other words. A person is precluded from expressing this experience by means of other words because using other words would imply a different primitive reaction, and hence a different experience; saying it otherwise would be saying something different. Numerically different experiences are counted as being the same experience when they receive the same verbal expression. If one person is inclined to use these words whereas another person is inclined to use other words, one cannot maintain that they have the same experience, only express it differently.

\section{Conclusion}

Failing to see that the concept of experience is modified is what lies at the root of the current controversy over whether synaesthesia is a sense-experience or a metaphor. One source of the conceptual pressure to classify synaesthesia as a sense-experience comes from the feeling that how a person describes his experience cannot be just a façon de parler. As some put this conviction: 'The link between real and

\footnotetext{
${ }^{19}$ For a recent Wittgensteinian developmental psychological view of the learning and meaning of psychological concepts, see Carpendale and Lewis (2004). See also ter Hark 2006.

${ }^{20}$ The point is not that people may not have synaesthetic experiences without saying anything. Wittgenstein's point is logical: the concept and hence the communication of synaesthesia requires the command of the primary use of language.
} 
synaesthetic experiences reflects more than metaphorical language or thought.' (Rich and Mattingley 2002, 43) Or as others interpret Luria's patient who described a person's voice as 'crumbly and yellow': 'The connection between the inducer and induced is so entrenched that the image is considered part of the percept's literal identity. For $\mathrm{S}$ to refer to a voice as 'crumbly and yellow' is to offer a literal rather than a metaphorical description.' (Martino and Marks 2001, 62-63) But the 'metaphor' involved is not a façon de parler which might be restated more directly, more literally and closer to the phenomenon, but is essential to it in the sense that it is constitutive of the experience. Consequently, to call it literal rather than metaphorical can only mean that the verbal expression of the experience is not an indirect formulation of the experience but the only way to formulate it, i.e. it is a secondary use of words.

\section{References}

Baron-Cohen, S., Wyke, M. A., \& Binnie, C. (1987). Hearing words and seeing colours: an experimental investigation of a case of synesthesia. Perception, 16, 761-767.

Baron-Cohen, S., Burt, L., Smith-Laittan, F., Harrison, J., \& Bolton, J. (1996). Synaesthesia: Prevalence and familiarity. Perception, 25, 1073-1080.

Budd, M. (1989). Wittgenstein's philosophy of psychology. Routledge.

Budd, M. (2006). The characterization of aesthetic qualities by essential metaphors and quasi-metaphors. British Journal of Aesthetics, 46, 133-143.

Carpendale, J., \& Lewis, C. (2004). Constructing an understanding of mind: the development of children's social understanding within social interaction. Behavioral and Brain Sciences, 27, 79-96.

Cavell, S. (1979). The claim of reason. Cambridge: Cambridge University Press.

Galton, F. (1883). Inquiries into human faculty and its development. London: MacMillan.

Ginsberg, L. A. (1923). A case of synaesthesia. American Journal of Psychology, 34, 582-589.

Goethe, J. (1971). The autobiography of Johann Wolfgang von Goethe, vol II, tr. S. Oxenford. Sidgwick and Jackson: London.

Grossenbacher, P. G., \& Lovelace, C. T. (2001). Mechanisms of synesthesia: Cognitive and physiological constraints. Trends in Cognitive Sciences, 5, 36-41.

ter Hark, M. R. M. (1990). Beyond the inner and the outer: Wittgenstein's philosophy of psychology. Dordrecht: Kluwer Academic.

ter Hark, M. R. M. (2006). Wittgenstein, pretend play and the transferred use of language. Journal of the Theory of Social Behavior, 36, 299-319.

James, W. (1890). The principles of psychology. Vol. 1. New York: Dover.

Johnston, P. (1993). Wittgenstein: Rethinking the inner. London: Routledge.

Köhler, W. (1929). Gestalt psychology. New York: Liveright.

Kripke, S. (1984). Wittgenstein on rules and private language. Oxford: Blackwell.

Marks, L. E. (1975). On coloured-hearing synesthesia: Cross-modal translations of sensory dimensions. Psychological Bulletin, 82, 303-331.

Marks, L. E. (1996). On perceptual metaphors. Metaphor and Symbolic Activity, 11, 39-66.

Martino, G., \& Marks, L. E. (2001). Synesthesia: Strong and weak. Current Directions in Psychological Science, 10, 61-66.

Mattingley, J. B., Payne, J., \& Rich, A. N. (2006). Attentional load attenuates synaesthetic priming effects in colour-grapheme synaesthesia. Cortex, 42, 213-221.

McGinn, C. (2004). Mindsight. Harvard University Press.

Mulhall, S. (2001). Seeing aspects. In H.-J. Glock (Ed.), Wittgenstein: a critical reader. Oxford: Blackwell.

Ramachandran, V. S., \& Hubbard, E. M. (2001). Synesthesia-a window into perception, thought and language. Journal of Consciousness Studies, 8, 3-34.

Rich, A. N., \& Mattingley, J. B. (2002). Anomalous perception in synaesthesia: a cognitive neuroscience perspective. Nature Reviews of Neuroscience, 3, 43-52. 
Rich, A. N., Bradshaw, J. L., \& Mattingley, J. B. (2005). A systematic, large-scale study of synaesthesia: Implications for the role of early experience in lexical-colour associations. Cognition, 98, 53-84.

Sartre, J. P. (1940). L'imaginaire. Paris: Gallimard.

Schulte, J. (1993). Experience and expression. Oxford: Blackwell.

Tilghman, B. R. (1984). But is it art?. Oxford: Blackwell.

Ward, J., \& Mattingley, J. B. (2006). Synaesthesia: an overview of contemporary findings and controversies. Cortex, 42, 129-136.

Werner, H. (1966). Intermodale Qualitäten (Synästhesien). Handbuch der Psychologie Bd. I, 1 hg. Von W. Metzger, Göttingen.

von Wright, H. (1982). Wittgenstein. Oxford: Blackwell. 